\title{
Assessing auditory evoked potentials of wild harbor porpoises (Phocoena phocoena)
}

\author{
Andreas Ruser, ${ }^{\text {a) }}$ Michael Dähne, ${ }^{\text {b) }}$ Abbo van Neer, Klaus Lucke, ${ }^{\text {c) }}$ Janne Sundermeyer, ${ }^{\text {d) }}$ \\ and Ursula Siebert \\ Institute for Terrestrial and Aquatic Wildlife Research, University of Veterinary Medicine Hannover, \\ Foundation, Büsum, SH, Germany
}

Dorian S. Houser

National Marine Mammal Foundation, San Diego, California 92106, USA

James J. Finneran

U.S. Navy Marine Mammal Program, Space and Naval Warfare Systems Center Pacific, San Diego, California 92152, USA

Eligius Everaarts and Jolanda Meerbeek

SOS Dolfijn, Harderwijk, Netherlands

Rune Dietz, Signe Sveegaard, and Jonas Teilmann

Department of Bioscience, Aarhus University, Frederiksborgvej 399, 4000 Roskilde, Denmark

(Received 6 November 2015; revised 10 June 2016; accepted 16 June 2016; published online 19 July 2016)

\begin{abstract}
Testing the hearing abilities of marine mammals under water is a challenging task. Sample sizes are usually low, thus limiting the ability to generalize findings of susceptibility towards noise influences. A method to measure harbor porpoise hearing thresholds in situ in outdoor conditions using auditory steady state responses of the brainstem was developed and tested. The method was used on 15 live-stranded animals from the North Sea during rehabilitation, shortly before release into the wild, and on 12 wild animals incidentally caught in pound nets in Denmark (inner Danish waters). Results indicated that although the variability between individuals is wide, the shape of the hearing curve is generally similar to previously published results from behavioral trials. Using $10-\mathrm{kHz}$ frequency intervals between 10 and $160 \mathrm{kHz}$, best hearing was found between 120 and $130 \mathrm{kHz}$. Additional testing using one-third octave frequency intervals (from 16 to $160 \mathrm{kHz}$ ) allowed for a much faster hearing assessment, but eliminated the fine scale threshold characteristics. For further investigations, the method will be used to better understand the factors influencing sensitivity differences across individuals and to establish population-level parameters describing hearing abilities of harbor porpoises. (C) 2016 Acoustical Society of America. [http://dx.doi.org/10.1121/1.4955306]
\end{abstract}

[WWA]

Pages: 442-452

\section{INTRODUCTION}

Anthropogenic noise has received much attention as a potential factor negatively affecting marine fauna (Huddleston, 2010; Slabbekoorn et al., 2010). In Europe, the most significant contributions of anthropogenic noise originate from shipping, seismic exploration, dredging, military exercises (Wright et al., 2013) and, in recent years, pile driving for offshore wind farms (Götz et al., 2009). The presence of high-amplitude impulsive sounds, common to pile driving and reflection seismology in northern Europe, has triggered a number of studies to assess the potential impact of ongoing construction work of offshore wind farms on harbor porpoises (Phocoena phocoena), an ubiquitous marine mammal species in these waters (e.g., Brandt et al., 2011; Dähne

\footnotetext{
a)Electronic mail: andreas.ruser@tiho-hannover.de

${ }^{b}$ Present address: German Oceanographic Museum, Stralsund, MV, Germany.

${ }^{c}$ Present address: Center for Marine Science and Technology, Curtin University, Perth, Australia.

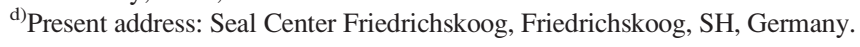

et al., 2013; Dähne et al., 2014; Kastelein et al., 2012a; Kastelein et al., 2013b; Tougaard et al., 2009a). Two general categories of impacts are of major concern: direct damage to the auditory system by intense sound in the vicinity of active pile driving (Lucke et al., 2009; Tougaard et al., 2015); and disturbance effects that potentially lead to behavioral alterations such as stress, loss of foraging opportunities or reduced foraging efficiency, disruption of social or breeding behavior, and other possible responses (Dähne et al., 2014).

Early assessments of the hearing abilities of harbor porpoises using behavioral methods revealed that this species hears best between 8 and $32 \mathrm{kHz}$ and that sensitivity declines sharply between 140 and $150 \mathrm{kHz}$ (Andersen, 1970). Over $30 \mathrm{yr}$ later, the hearing ability of a harbor porpoise in human care was reassessed by using psychoacoustic methods, to aid the design of acoustic alarms meant to prevent porpoise bycatch in gillnets (Kastelein et al., 2010). Porpoise hearing was also assessed using electrophysiological methods (Bibikov, 1992; Popov et al., 1986). In these studies, hearing sensitivity was found to be more sensitive around $130 \mathrm{kHz}$, 
at a much higher frequency range than previously reported by Andersen (1970). Thus, only a low number of hearing measurements have been made so far on harbor porpoises. The methods and results vary considerably between the studies making it difficult to determine whether or not the collective hearing threshold data is representative of harbor porpoises as a species. This subsequently impedes the ability of regulators to confidently target frequencies of sound most likely to affect harbor porpoises. Furthermore, how hearing abilities vary with age, gender, and across individuals is not fully understood, yet it is fundamental to understanding the potential impact of anthropogenic induced sound on harbor porpoise populations.

Psychophysical studies conducted with marine mammals typically rely on a limited number of animal subjects. This is due to the small number of animals in human care available for research, as well as the amount of time required for training the specific behaviors required for such studies. The limited number of marine mammals that can be tested via psychophysical means make it difficult to account for variability on population-level (e.g., age, gender, etc.). Electrophysiological hearing tests can be performed in many marine mammals with little to no training and the hearing test data can be collected quickly (minutes to hours). The approach has provided good estimates for the best frequency range of hearing when compared to behavioral assessments in the same bottlenose dolphin subjects (Tursiops truncatus; Houser and Finneran, 2006a; Schlundt et al., 2007). However, there are differences in sensitivity estimates (or thresholds) with the greatest differences typically occurring at the highest and lowest limits of the frequency range of hearing. Furthermore, the magnitude of the differences may vary with the methods used (Finneran and Houser, 2006; Houser and Finneran, 2006a; Schlundt et al., 2007; Yuen et al., 2005). Nevertheless, electrophysiological approaches have enabled large scale studies to be undertaken in odontocete species that demonstrate population-level variability in hearing, including changes in hearing sensitivity and the frequency range of hearing associated with age and gender (Houser and Finneran, 2006b; Popov et al., 2005).

In the study described here, electrophysiological measurements of hearing were made on 27 harbor porpoises with the goal of better quantifying variation in the range of hearing and hearing sensitivity in this species. Testing was done opportunistically, utilizing porpoises either incidentally caught in pound nets or animals undergoing rehabilitation following a live stranding. Trials were conducted on animals from the North and Baltic Seas, regions that are subject to increased anthropogenic noise activity due to wind farm construction and operation, shipping, and seismic exploration.

\section{MATERIALS AND METHODS}

Electrophysiological measurements of hearing abilities in harbor porpoises were performed on wild animals from the inner Danish waters (Fig. 1), which were incidentally caught in Danish pound nets, and on live-stranded animals rehabilitated at the SOS Dolfijn (Harderwijk, Netherlands). For each animal an electrophysiological procedure in which auditory evoked potentials (AEPs) were recorded in response to varying levels of acoustic stimuli was performed.

\section{A. Animal subjects and study locations}

The locations where wild porpoises were caught in static pound nets were spread along the inner Danish waters, within the range of the population residing in the Belt Sea and adjacent waters (Fig. 1). The animals can swim freely in those pound nets. When discovered, Danish fisherman reported the presence of a by-caught porpoise to the investigators at Aarhus University. Upon notification, equipment and personnel were gathered and the research team travelled to the site of the pound net. The earliest arrival at the study site was approximately $5 \mathrm{~h}$ after the notification that an animal had been caught, the latest after $24 \mathrm{~h}$, depending on

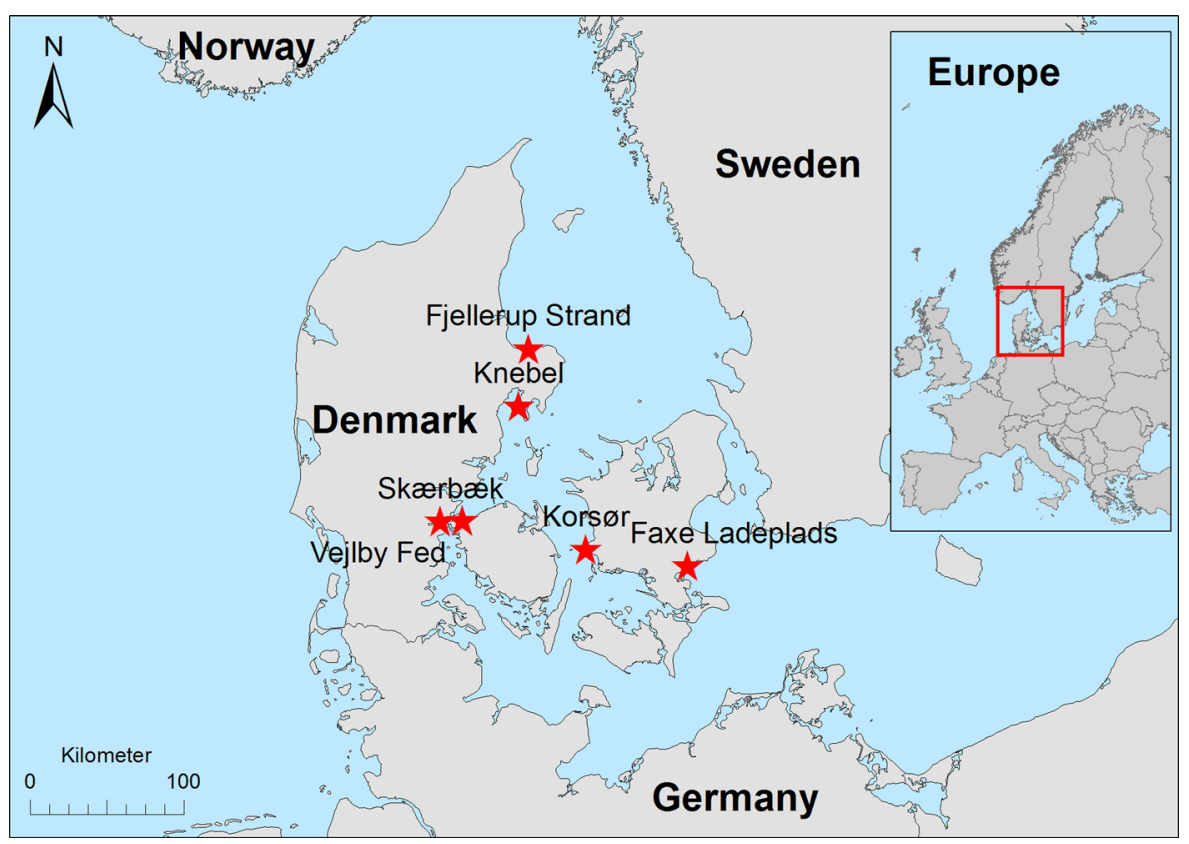

FIG. 1. (Color online) Locations of porpoise ABR-hearing trials in the inner Danish waters. 
TABLE I. Overview of porpoises assessed in the inner Danish waters. Age was estimated using methods described in Benke et al. (1998).

\begin{tabular}{lcccccc}
\hline \hline Date & Id & Location & Gender & $\begin{array}{c}\text { Weight } \\
(\mathrm{kg})\end{array}$ & $\begin{array}{c}\text { Length } \\
(\mathrm{cm})\end{array}$ & $\begin{array}{c}\text { Age } \\
\text { estimated }\end{array}$ \\
\hline Jul. 2011 & wild_01 & Fjellerup & male & 24 & 117 & subadult \\
Jul. 2011 & wild_02 & Fjellerup & female & 28 & 128 & subadult \\
Aug. 2011 & wild_03 & Knebel & female & 44 & 141 & adult \\
Sep. 2011 & wild_04 & Knebel & female & 39 & 147 & adult \\
Aug. 2012 & wild_05 & Skærbæk & male & 39 & 145 & adult \\
Apr. 2013 & wild_06 & Korsør & male & 54 & 141 & adult \\
May 2013 & wild_07 & Korsør & male & 51 & 149 & adult \\
May 2013 & wild_08 & Skærbæk & male & 31 & 116 & subadult \\
Aug. 2013 & wild_09 & Faxe & male & 38 & 146 & adult \\
Mar. 2014 & wild_10 & Vejlby Fed & female & 36 & 122 & subadult \\
Apr. 2014 & wild_11 & Fjellerup & male & 19 & 115 & subadult \\
Apr. 2014 & wild_12 & Fjellerup & male & 36 & 127 & subadult \\
\hline \hline
\end{tabular}

daylight, wind, wave height, and availability of personnel. After arrival of the team, the bottom of the net was lifted up and the porpoise was placed on the fisherman's boat for an initial health check by the attending veterinarian. Standard biological parameters such as length and weight were recorded and blood and blow samples were collected. A good health condition determined by the veterinarian was required before a porpoise was placed into the custom-built stretcher used for the hearing test. Throughout the health assessment and the following hearing tests, the health condition of the porpoise was continuously monitored by the attending veterinarian. Weather was a limiting factor for experiments in the wild; strong wind and waves as well as rain often made hearing tests impossible and not all bycaught animals were used in hearing test procedures. From 2011 until 2014, 12 harbor porpoises were fully assessed (Table I).

Measurements on rehabilitating porpoises were performed at the SOS Dolfijn in Harderwijk as part of standard medical evaluations conducted prior to the animals being released in the North Sea. In principle, the experimental set-up was the same as in the wild, the distance of the transducers presenting the stimulus to the porpoise and the position of the hydrophone to control the sound pressure level (SPL) were similar. The animal was held by a caretaker during the measurement procedure; the caretaker stood lateral to the animal and out of the direct sound path from the transducer to the animal. From 2012 to 2014, the hearing ability of 15 rehabilitated harbor porpoises was assessed (Table II).
TABLE II. Overview of porpoises assessed in rehabilitation at the SOS Dolfijn (Harderwijk, NL). Age was estimated using methods described in Benke et al. (1998).

\begin{tabular}{lccccc}
\hline \hline Date & Id & Gender & $\begin{array}{c}\text { Weight } \\
(\mathrm{kg})\end{array}$ & $\begin{array}{c}\text { Length } \\
(\mathrm{cm})\end{array}$ & $\begin{array}{c}\text { Age } \\
\text { estimated }\end{array}$ \\
\hline Apr. 2012 & rehab_01 & female & 22 & 105 & subadult \\
Apr. 2012 & rehab_02 & male & 27 & 112 & subadult \\
Jun. 2012 & rehab_03 & female & 31 & 121 & subadult \\
Jun. 2012 & rehab_04 & male & 22 & 103 & subadult \\
Jun. 2012 & rehab_05 & female & 27 & 116 & subadult \\
Jun. 2012 & rehab_06 & male & 20 & 100 & subadult \\
May 2013 & rehab_07 & female & 31 & 125 & subadult \\
May 2013 & rehab_08 & female & 50 & 148 & adult \\
May 2013 & rehab_09 & male & 23 & 107 & subadult \\
May 2013 & rehab_10 & female & 31 & 124 & subadult \\
Jun. 2014 & rehab_11 & male & 28 & 108 & subadult \\
Jun. 2014 & rehab_12 & male & 27 & 115 & subadult \\
Jun. 2014 & rehab_13 & male & 24 & 108 & subadult \\
Jun. 2014 & rehab_14 & female & 32 & 125 & subadult \\
Jun. 2014 & rehab_15 & male & 46 & 146 & adult \\
\hline \hline
\end{tabular}

\section{B. Experimental setup and stimulus presentation}

The setup for the measurements in the wild and at the rehabilitation center was similar. In both locations, the porpoise was kept at the surface so that the blowhole was just above the water surface to allow the porpoise to breathe freely. The stimulus sound projector was placed $1 \mathrm{~m}$ in front of the porpoise at a depth of $50 \mathrm{~cm}$ (Fig. 2). The receiving hydrophone, used to determine the actual SPL at the porpoise, was placed $30 \mathrm{~cm}$ lateral to the middle of the lower jaw. This was as close to the porpoise that the hydrophone could be placed without causing irritation and stress to the animal. At the SOS Dolfijn, all anticipated sources of acoustic and electromagnetic interference under facility control (e.g., lights, pumps) were turned off during the trials.

Sinusoidal amplitude modulated (SAM) tones were used as stimuli to produce an auditory steady state response (ASSR), the amplitude and phase of which was used in the hearing threshold determination. Stimuli were digitally generated with a Panasonic Toughbook CF30, converted to ana$\log$ with a $1 \mathrm{MHz}$ update rate and 16-bit resolution (NI USB 6251, National Instruments, USA), band pass filtered $(100 \mathrm{~Hz}-250 \mathrm{kHz}, 24 \mathrm{~dB} /$ octave; Krohn-Hite, USA), and attenuated before being applied to a TC4033 transducer (Teledyne Reson, DK) in the frequency range from 10 to $160 \mathrm{kHz}$. Stimulus levels were manipulated using a combination of a digitally controlled analog attenuator (0-70 dB in

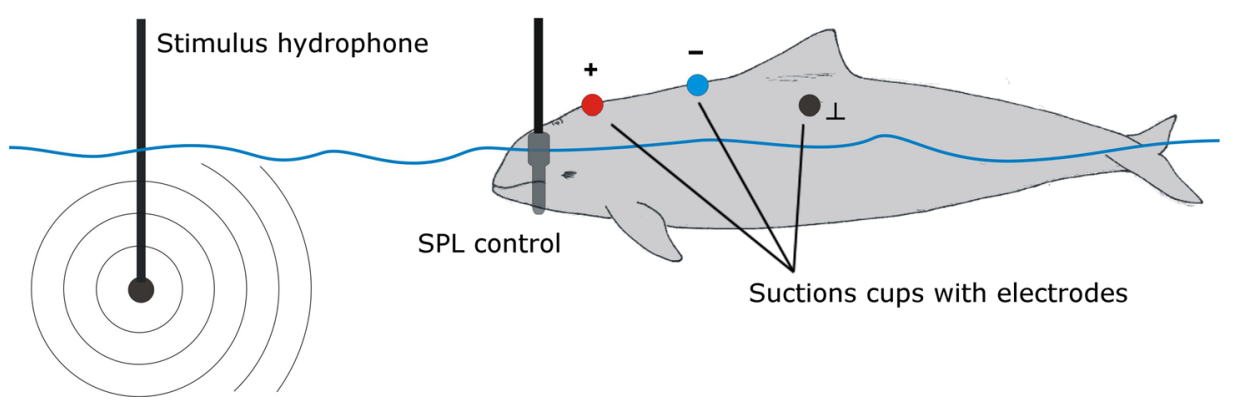

FIG. 2. (Color online) Experimental setup. 
$10 \mathrm{~dB}$ steps) and varying the voltage output of the USB6251. Each test stimulus consisted of four SAM tones presented simultaneously with different amplitude modulation (AM) rates (Finneran and Houser, 2007), and are thus termed a 4-component SAM stimulus (4-SAM). SAM tones elicit an ASSR, which is a periodic neural signal that occurs at the frequency of amplitude modulation. The ASSR may be analyzed in the frequency domain using established techniques for objective, statistically based response detection methods (Dobie and Wilson, 1996; Stapells et al., 1987).

When multiple SAM tones are combined, the ASSR of each carrier frequency (tone) can be independently analyzed providing different modulation rates (see Table III for the AM frequencies used) are used for each. Thus, as has been performed with bottlenose dolphins, amplitude modulation rates of the individual carrier frequencies within a 4-SAM were varied so that component signals could be individually analyzed within the frequency domain (Finneran and Houser, 2007). The AM frequencies used here are based on different studies on the so-called modulation rate transfer function (Linnenschmidt et al., 2013; Lucke, 2008; Lucke et al., 2007). Each carrier frequency within a 4-SAM stimulus was $100 \%$ amplitude modulated. Signals were $60 \mathrm{~ms}$ in duration, including a 1-ms cosine envelope rise and fall with a total epoch length of $71 \mathrm{~ms}$ (i.e., $9 \mathrm{~ms}$ of silence followed each stimulus).

When the investigations started in 2011, hearing thresholds were obtained by conducting four measurements, each with different 4-SAM stimuli (Table III, Set A, starting 2011). The tested frequencies within a 4-SAM stimulus were separated by $40 \mathrm{kHz}$. Between the four 4SAM stimuli used, differences in the lowest frequency tested differed by integer multiples of $10 \mathrm{kHz}$. This allowed the hearing range between 10 and $160 \mathrm{kHz}$ to be covered in

TABLE III. Test frequencies and associated amplitude modulation (AM) rates for 4-component SAM stimuli in the used hearing threshold assessment. The frequency spacing of the component frequencies were changed closest to octave steps starting in 2013 to decrease the data collection time necessary for audiogram determination.

\begin{tabular}{lrrcrr}
\hline \hline $\begin{array}{l}\text { Set A } \\
\text { Starting }\end{array} 211$ & $\begin{array}{c}\text { Test } \\
\text { frequencies } \\
(\mathrm{kHz})\end{array}$ & $\begin{array}{c}\text { AM } \\
\text { rates } \\
(\mathrm{kHz})\end{array}$ & $\begin{array}{c}\text { Set B } \\
\text { Starting } \\
2013\end{array}$ & $\begin{array}{c}\text { Test } \\
\text { frequencies } \\
(\mathrm{kHz})\end{array}$ & $\begin{array}{c}\text { AM } \\
\text { rates } \\
(\mathrm{kHz})\end{array}$ \\
\hline SAM stimulus & $\mathbf{1 0}$ & 0.90 & SAM stimulus & $\mathbf{1 6}$ & 1.10 \\
$\# 1$ & $\mathbf{5 0}$ & 1.10 & \#1 & $\mathbf{3 2}$ & 1.15 \\
& $\mathbf{9 0}$ & 1.16 & & $\mathbf{6 4}$ & 1.20 \\
& $\mathbf{1 3 0}$ & 1.23 & & $\mathbf{1 2 8}$ & 1.25 \\
SAM stimulus & $\mathbf{2 0}$ & 0.90 & SAM stimulus & $\mathbf{2 0}$ & 1.10 \\
\#2 & $\mathbf{6 0}$ & 1.10 & \#2 & $\mathbf{4 0}$ & 1.15 \\
& $\mathbf{1 0 0}$ & 1.16 & & $\mathbf{8 0}$ & 1.20 \\
SAM stimulus & $\mathbf{1 4 0}$ & 1.23 & & $\mathbf{1 5 0}$ & 1.25 \\
\#3 & $\mathbf{3 0}$ & 0.90 & SAM stimulus & $\mathbf{2 5}$ & 1.10 \\
& $\mathbf{7 0}$ & 1.10 & \#3 & $\mathbf{5 0}$ & 1.15 \\
& $\mathbf{1 1 0}$ & 1.16 & & $\mathbf{1 0 0}$ & 1.20 \\
SAM stimulus & $\mathbf{1 5 0}$ & 1.23 & & $\mathbf{1 6 0}$ & 1.25 \\
\#4 & $\mathbf{4 0}$ & 0.90 & & & \\
& $\mathbf{8 0}$ & 1.10 & & & \\
\hline \hline
\end{tabular}

$10 \mathrm{kHz}$ steps. A total of 12 porpoises were tested using this configuration of stimuli (six at the SOS Dolfijn, six in the wild). As testing progressed it was deemed necessary to reduce the time required for the procedure and the combination of frequencies constituting the 4-SAM stimuli was changed to octave steps (when appropriate and feasible) in 2013. This allowed for testing one-third octave band intervals covering the frequency range of interest with only three different 4-SAM stimuli (Table III). A total of 15 porpoises were tested with this SAM stimulus configuration (nine at the SOS, six in the wild).

The received levels of test stimuli were measured with a hydrophone placed near the porpoise or attached to the frame holding the porpoise (TC4014 or TC4013, respectively; Teledyn Reson, DK). Signals were amplified by $20 \mathrm{~dB}$ and band pass filtered from 1 to $180 \mathrm{kHz}$ (ETEC B 1501, DK) and then digitized at $500 \mathrm{kHz}$ with a 16-bit DAQ-card (NI USB 6251, National Instruments, USA), which was part of the Evoked Response Study Tool (EVREST; Finneran, 2009; Finneran et al., 2008). All hearing test results presented in this work were performed at the surface in different environments. The lower jaw of the porpoise was situated around $10-20 \mathrm{~cm}$ below the surface. Therefore the received SPLs had to be measured during all trials and for all frequencies. The variability of the SPLs over the full frequency range at the different locations was within $\pm 3 \mathrm{~dB}$, when the environmental conditions were good. The SPL control measurements for the hearing tests on wild porpoises at sea were strongly influenced by the wave height resulting in movements of the measuring platform. Due to the changes in the position of the hydrophone in the water column, SPLs were underestimated often with large deviations from the mean. Two different placements of hydrophones were tested to counteract these procedural variations: A TC4014 placed $20-30 \mathrm{~cm}$ distally to the porpoise and/or a smaller TC4013 was directly attached to the construction holding the porpoise in position. All hearing threshold measurements were corrected with the mean value of the SPLs measured under good conditions.

\section{Evoked response measurement}

Both stimulus presentation and ASSR recordings were collected from each porpoise with the EVREST system. The EVREST software was run on the same PC previously described for stimulus presentation (Panasonic Toughbook CF30). Brainstem responses were recorded using $10 \mathrm{~mm}$ gold-plated electrodes imbedded in suction cups and placed at three positions between the blowhole and the dorsal fin of the porpoise, as previously reported (Lucke et al., 2007). The active $(+)$ electrode was placed $7 \mathrm{~cm}$ behind the blowhole, the inverting electrode (-) along the dorsal midline of the porpoise between the blowhole and dorsal fin, and the ground electrode $(\perp)$ on the left or right side of the dorsal fin (Fig. 2). The ASSRs measured at the electrodes were amplified (100-dB gain), and filtered $(0.3-3 \mathrm{kHz})$ with a biopotential amplifier (CP511, Grass Technologies, USA), then digitized at $50 \mathrm{kHz}$ and 16-bit resolution via the USB-6251 data acquisition board. The reject level used in EVREST to 
exclude electrical responses not evoked by the hearing was $20 \mu \mathrm{V}$. Recordings were synchronized to the stimulus onset and averaged until 1024 evoked response epochs were obtained, at which point the next stimulus level was tested. Collection of the evoked response for a single stimulus sound pressure level took $71 \mathrm{~s}$, and overall, six to 10 different SPLs were tested by an automated staircase routine in order to determine the hearing threshold using magnitudesquared coherence (MSC) calculation with 16 sub-averages and $\alpha=1$ (Dobie and Wilson, 1989; Finneran et al., 2007).

\section{Background noise recordings}

Noise levels were recorded with a hydrophone (TC4032, Teledyn Reson, DK), amplifier $(+20 \mathrm{~dB})$ with band pass filter $(100 \mathrm{~Hz}-180 \mathrm{kHz}$, ETEC $1501, \mathrm{DK})$, and a DAQ-card (NI USB 6251, National Instruments, USA) with a sample rate of $200 \mathrm{kHz}$ at the SOS Dolfijn and $400 \mathrm{kHz}$ in the wild. One-third octave levels (in $\mathrm{dB}$ re $1 \mu \mathrm{Pa}$ ) of background noise were measured before and after each hearing test. Background noise at sea changed during the course of testing; noise conditions at sea changed within short time periods (e.g., passing ships), or slowly during the trial (changing weather). To account for these circumstances, an automated routine was initiated in 2014 to record 10-s samples at regular time intervals of 2 min to allow for the evaluation of noise variability throughout the trial.

\section{E. Data analysis}

Signals were analyzed during the trials using a staircase procedure based on a magnitude squared coherence test (MSC) and controlled afterwards by post-filtering the ABR response (band pass filtered $0.3-3 \mathrm{kHz}, 72 \mathrm{~dB} /$ octave). When an ABR response was obviously disturbed (waveform, amplitude, and phase) due to, e.g., changes of the environment (rain or upcoming stronger waves), the background noise level or movements of the animal, results for the individual transmitted sound pressure levels were neglected in post analysis. This resulted in a higher deviation for the threshold determined or an omission of the full threshold measurement. The thresholds were defined as the midpoint between the lowest stimulus level corresponding to the last MSC response detected and the highest stimulus level where no response was detected. Following the determination of frequencyspecific thresholds, the median, the quantiles (0.25 and 0.75), the whiskers and outliers according to Borcard et al. (2011) were calculated using the $\mathrm{R}$ environment ( $\mathrm{R}$ Core Team, 2014) to visualize thresholds determined for the two locations (Fig. 6) as well as for the two SAM stimulus sets (Set A and Set B from Table III in Fig. 7).

\section{F. Ethics statement}

Auditory threshold measurements conducted on harbor porpoises in Danish waters were conducted under permission issued to Jonas Teilmann, Aarhus University by the Danish Nature Agency (Danish Ministry of Environment, NST-34460016) and the Animal Experiments Inspectorate (Danish Ministry of Food, Agriculture and Fisheries, 2010/561-1801).
Auditory threshold measurements on porpoises in rehabilitation were conducted at the SOS Dolfijn under a permit to rehabilitate small cetaceans (exemption of articles 9 and 13.1 of "Flora en Fauna wet") and issued by the Dutch Ministry of Economic Affairs to SOS Dolfijn. The measurements at SOS Dolfijn were part of the regular medical screening conducted during the rehabilitation process (i.e., adequacy of hearing determined before a release determination was made). All trials were conducted adhering to the respective ethical principles as well as to the relevant international and national guidelines for animal experiments and under constant supervision of an experienced veterinarian. Condition and potential stress of the animal from handling and testing was monitored by the attending veterinarian and testing was immediately halted if observed. One test was aborted based on the veterinarian's assessment of the animal.

\section{RESULTS}

Hearing tests were completed with six animals at the SOS Dolfijn rehabilitation facility using $10 \mathrm{kHz}$ frequency spacing and nine with a one-third octave frequency spacing (Fig. 4) Similarly, hearing tests conducted within the Danish Baltic Sea were completed with six animals using $10 \mathrm{kHz}$ frequency spacing and six with a one-third octave frequency spacing (Fig. 5). The audiograms were typically odontocete in shape, showing a skewed U-shape when hearing was tested at the lowest frequency of $10 \mathrm{kHz}$; the U-shape was not obvious in animals tested at one-third octave steps where the lowest tested frequency was $16 \mathrm{kHz}$. The results of tests using both frequency spacing showed high variation for the hearing thresholds between the individuals.

The median thresholds for the Baltic Sea porpoises in the frequency range from 25 to $110 \mathrm{kHz}$ were $70-75 \mathrm{~dB}$ re $1 \mu \mathrm{Pa}$ [Fig. 6(a)] and the lowest value of $\sim 63 \mathrm{~dB}$ re $1 \mu \mathrm{Pa}$ was found at $128 \mathrm{kHz}$. In comparison, the median thresholds of the rehabilitated porpoises were 5 to $10 \mathrm{~dB}$ lower for frequencies between 25 and $130 \mathrm{kHz}$ with a best hearing value of $\sim 56 \mathrm{~dB}$ re $1 \mu \mathrm{Pa}$ at $128 \mathrm{kHz}$ [Fig. 6(b)]. For all animals in which a full range of hearing was tested, a slight decrease in

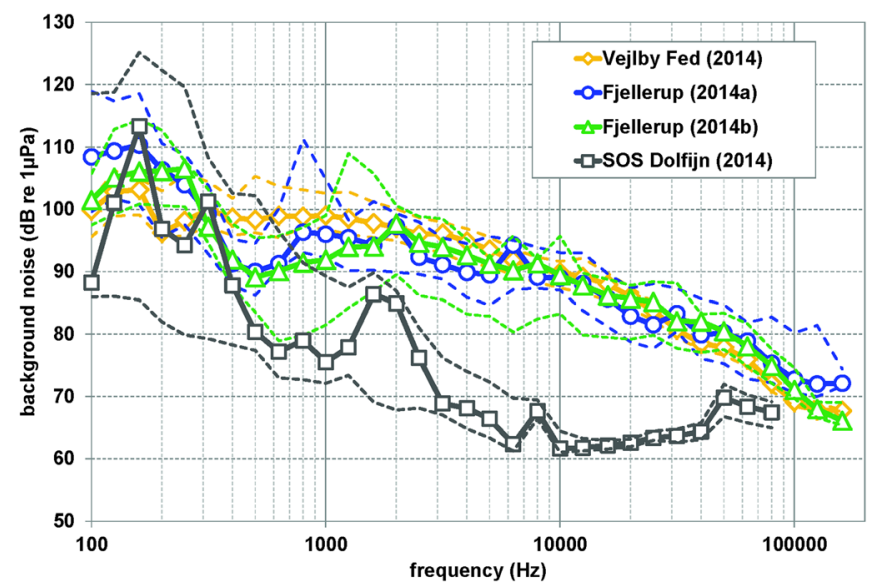

FIG. 3. (Color online) Mean one-third octave background noise level (solid lines with symbols) for the indoor (at the SOS Dolfijn, NL) and outdoor trials (Vejlby Fed and Fjellerup, DK) in 2014. The dotted lines indicate the maximum and minimum values of the spectra used for averaging. 

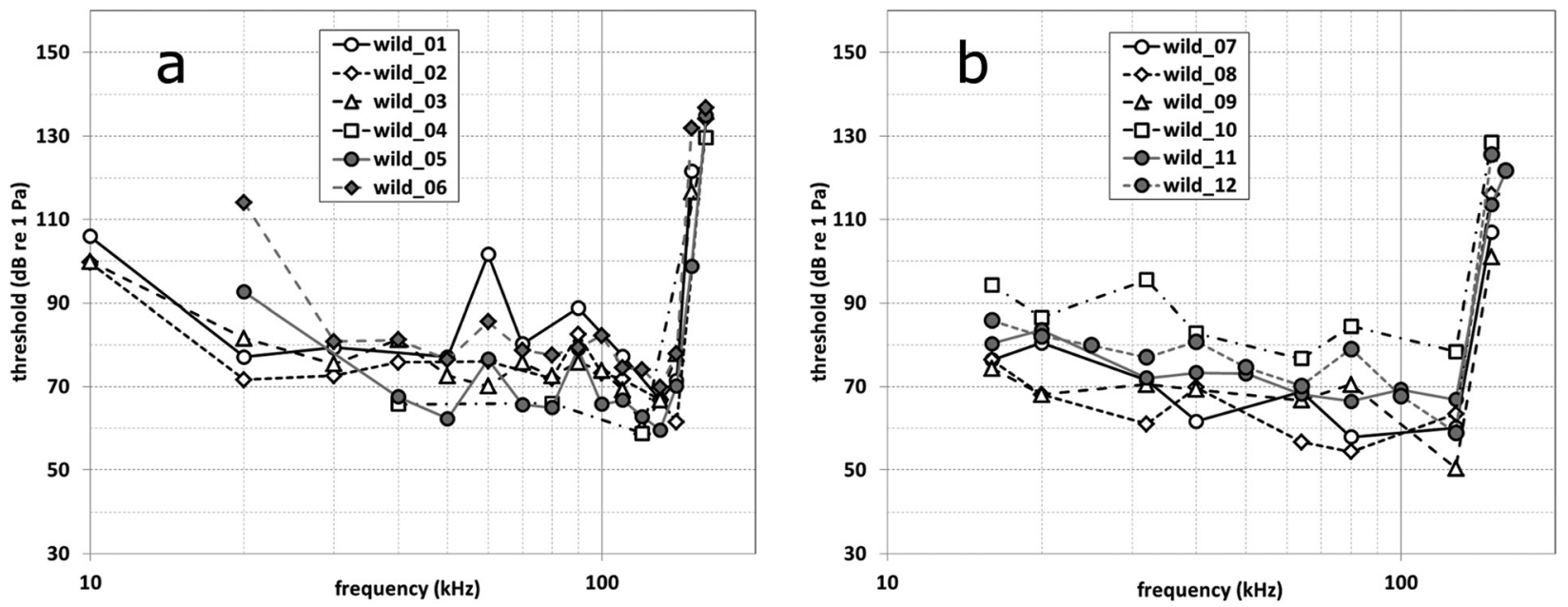

FIG. 4. Hearing thresholds for the porpoises in rehabilitation [(a) $10 \mathrm{kHz}$ frequency spacing, (b) one-third octave frequency spacing].
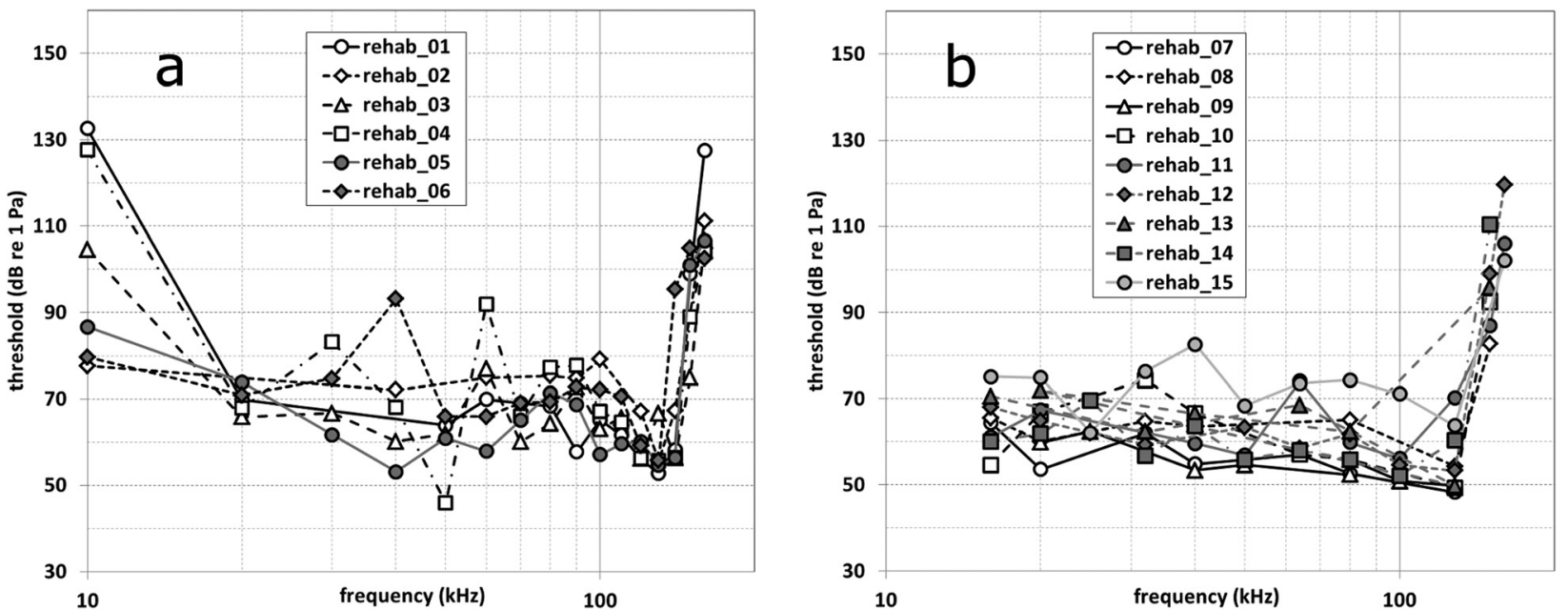

FIG. 5. Hearing thresholds for the porpoises from the inner Danish waters [(a) $10 \mathrm{kHz}$ frequency spacing, (b) one-third octave frequency spacing].
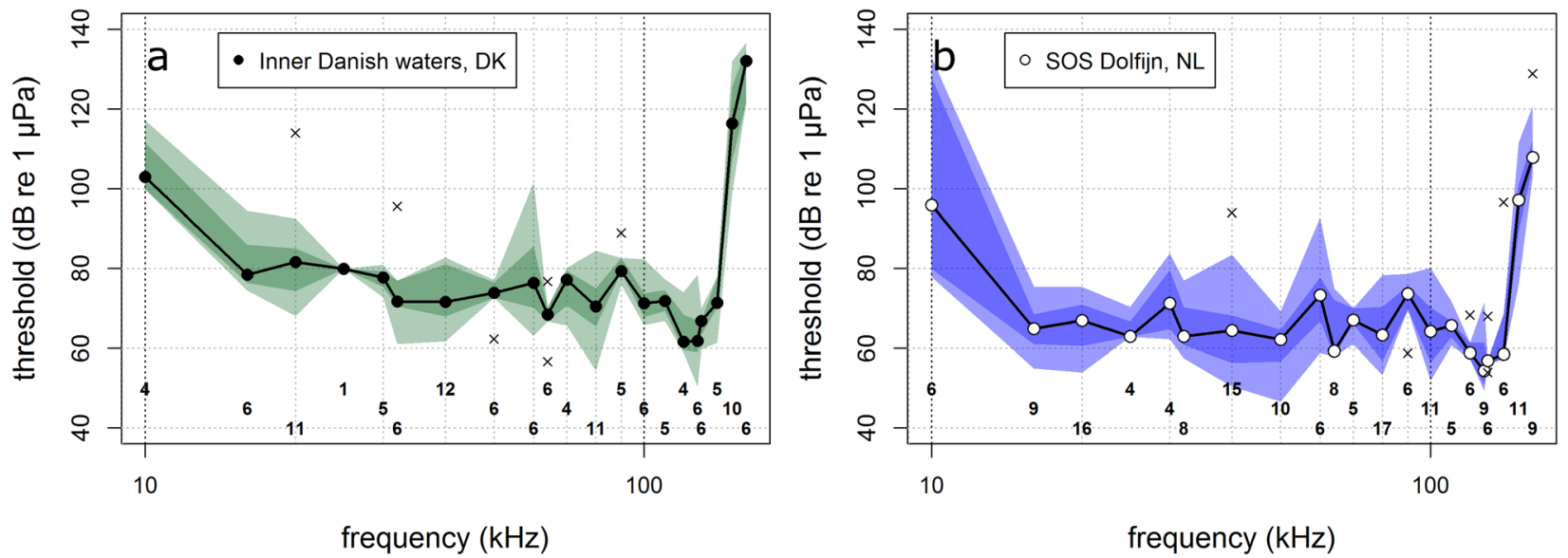

FIG. 6. (Color online) Thresholds for the porpoises (a) from the Danish Baltic Sea and (b) the rehabilitated animals at the SOS Dolfijn [median: black filled circles connected with a black line, quantiles 0.25 and 0.75: dark colored area, whiskers: light colored area according to Borcard et al. (2011)]. The numbers within the plot area representing the thresholds determined at the certain frequencies. 
hearing sensitivity at frequencies below $25 \mathrm{kHz}$ and a sharp decline in sensitivity for frequencies $\geq 140 \mathrm{kHz}$ was detected.

Noise levels calculated across one-third octave bands, both at-sea and at the SOS Dolfijn, are presented in Fig. 3. Background noise levels at the SOS Dolfijn, especially for frequencies $<4 \mathrm{kHz}$, were strongly affected by sounds coming from the nearby Dolfinarium (Harderwijk, NL) with which it is associated. Even though all pumps and lights of the SOS Dolfijn facility were turned off for the hearing tests, some modest electrical noise spikes at 2,8 , and $50 \mathrm{kHz}$ were observed. The noise levels below $10 \mathrm{kHz}$ sometimes increased during the measurements by $10-20 \mathrm{~dB}$ for several minutes and then went back to normal, presumably due to operations at the adjacent Dolfinarium (Harderwijk, NL). The background noise measurements at sea (Vejlby Fed and Fjellerup; Fig. 3) showed maximum mean differences from 0.1 to $2 \mathrm{kHz}$ of $10-20 \mathrm{~dB}$ within the one-third octave bands. Above $10 \mathrm{kHz}$, the background noise levels recorded at sea were quite similar regardless of location (within $\sim 2 \mathrm{~dB}$, except the 130 and $160 \mathrm{kHz}$ values for Fjellerup, 2014a in Fig. 3). In comparison to the background noise measured at the SOS Dolfijn, the outdoor noise levels are $\geq 20 \mathrm{~dB}$ higher in the frequency range of $400 \mathrm{~Hz}-40 \mathrm{kHz}$. Although noise levels decreased with increasing frequency, the noise levels recorded at sea generally did not approximate that of the SOS Dolfijn until the highest frequencies recorded. Nevertheless, for the frequencies of interest, the background noise at the SOS Dolfijn provided the better of the test environments.

\section{A. Comparison of the frequency-sets used}

The differences in the tonal frequency intervals used during testing (see Sec. IIB) and the effect on the shape of the audiograms of the porpoises are shown in Fig. 7 and Fig. 8. For frequency interval Sets A and B (refer to Table III), the hearing sensitivity showed a sharp decrease at frequencies $\geq 140 \mathrm{kHz}$. Between 30 and $130 \mathrm{kHz}$, the median sensitivity for both test sets showed a slightly different shape. The audiogram resulting from use of the Set B

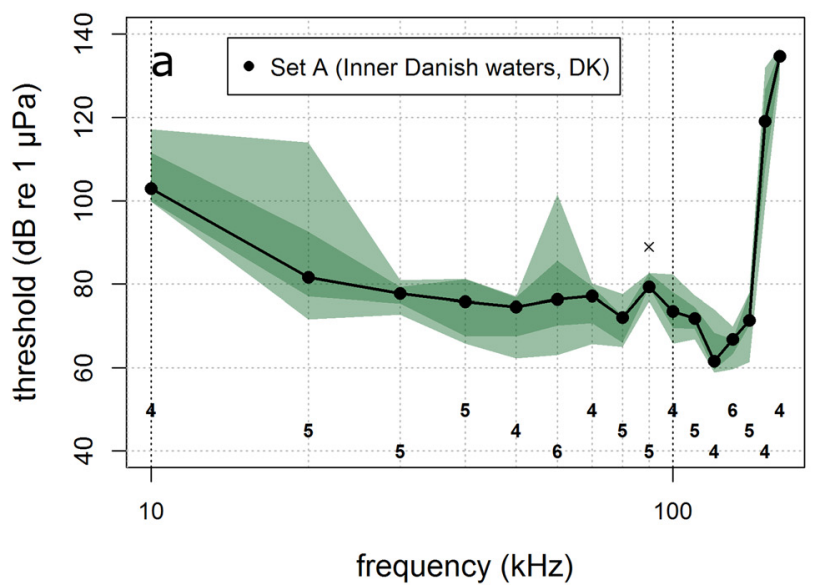

intervals was associated with a more "flattened" sensitivity curve. The one-third octave frequency steps for Set B eliminated the dip in the frequency range from 120 to $130 \mathrm{kHz}$, which is clearly observable for the $10 \mathrm{kHz}$ frequency steps used in Set A. Tests conducted with Set A showed a decrease in hearing sensitivity at $10 \mathrm{kHz}$ that was not observed with the Set B spacing $(10 \mathrm{kHz}$ was not sampled with Set B). The $10 \mathrm{kHz}$ threshold was also associated with a large variation in sensitivity estimates. The differences in determined hearing thresholds at $10 \mathrm{kHz}$ observed with Set $\mathrm{A}$ in this study are big and the decrease of hearing sensitivity is possibly not conclusive.

\section{DISCUSSION}

Historically, knowledge about the hearing ability of harbor porpoises was limited to a small number of animals. Andersen (1970) first determined an audiogram on a female porpoise using behavioral methods, although noise limitations to the thresholds estimates obtained during the study could not be determined, as the background noise was not reported. On two later occasions, Kastelein et al. (2010); Kastelein et al. (2015) determined behavioral audiograms on a 1.5 and a 3 yr old male porpoise. These latter two studies, which were conducted throughout a period of 1-1.5 yr, were performed in low ambient noise and provide greater confidence in the threshold estimates. Popov et al. (2005) used evoked potential methods to determine the audiograms of the related Yangtze finless porpoise (Neophocaena phocaenoides asiaorientalis); two animals were studied, an $8 \mathrm{yr}$ old male and a $5 \mathrm{yr}$ old female, but background noise levels were again not reported.

This is the first study to test the hearing of such a large number of wild porpoises. We could show that harbor porpoises have a broad hearing range between 16 to $140 \mathrm{kHz}$ with the highest sensitivity at $\sim 130 \mathrm{kHz}$. For frequencies above $140 \mathrm{kHz}$ a sharp decline in sensitivity was detected. Despite some variability in sensitivity between individuals, equivalent audiogram shapes (Fig. 4 and Fig. 5) were observed.

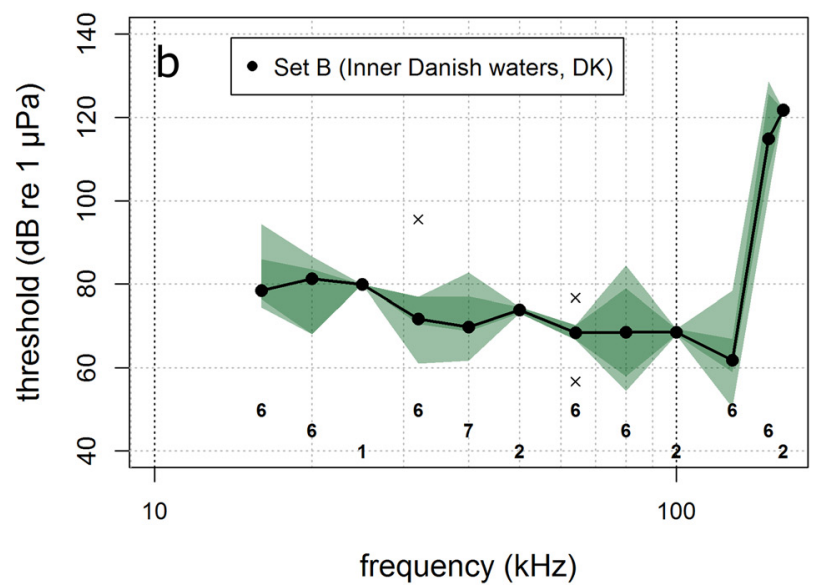

FIG. 7. (Color online) Thresholds for the porpoises from the inner Danish waters split for the hearing thresholds determined with (a) SAM Set A and (b) SAM Set B described in Table III [median: black filled circles connected with a black line, quantiles 0.25 and 0.75 : dark colored area, whiskers: light colored area according to Borcard et al. (2011)]. The numbers within the plot area representing the thresholds used at the certain frequencies. 

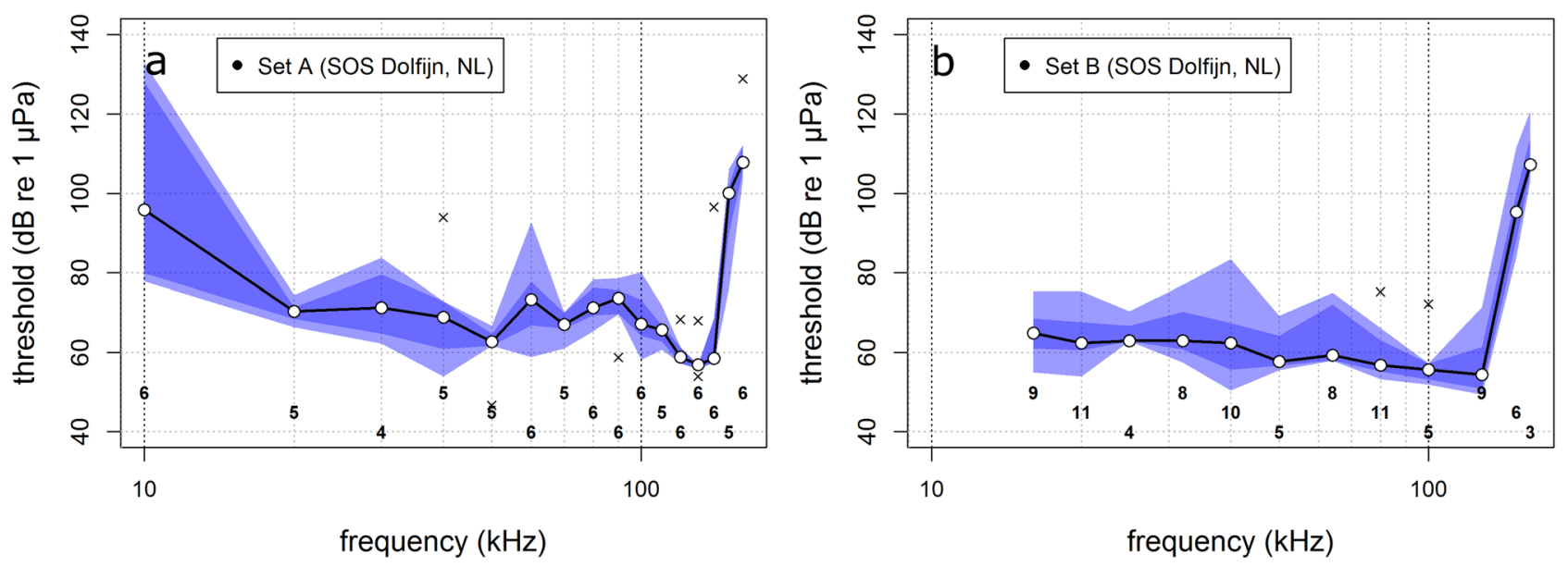

FIG. 8. (Color online) Thresholds for the porpoises from the rehabilitated animals at the SOS Dolfijn split for the hearing thresholds determined with (a) SAM Set A and (b) SAM Set B described in Table III [median: black filled circles connected with a black line, quantiles 0.25 and 0.75 : dark colored area, whiskers: light colored area according to Borcard et al. (2011)]. The numbers within the plot area representing the thresholds used at the certain frequencies.

A comparison of prior audiograms collected via behavioral methods with the results presented here illustrates some distinct differences (Fig. 9). Thresholds determined by behavioral methods are lower than the results of this study, but the form of the curve is comparable with respect to the limits of hearing and the frequency range of best hearing sensitivity. These types of differences are not uncommon when comparing AEP and behavioral thresholds. Prior comparisons of AEP and behavioral methods under various test conditions within the same subject have demonstrated that AEP threshold estimates can differ from behavioral thresholds by up to $20 \mathrm{~dB}$, depending upon the method used for estimating threshold (Houser and Finneran, 2006a; Yuen et al., 2005). Furthermore, the frequency of the auditory test stimuli as well as the proximity/distance of the subject to acoustic boundaries (surface) during the measurements affects the resulting thresholds. Consequently, when behavioral and AEP methodologies are more harmonized, these differences can be substantially minimized (Schlundt et al., 2007). Differences in the low and

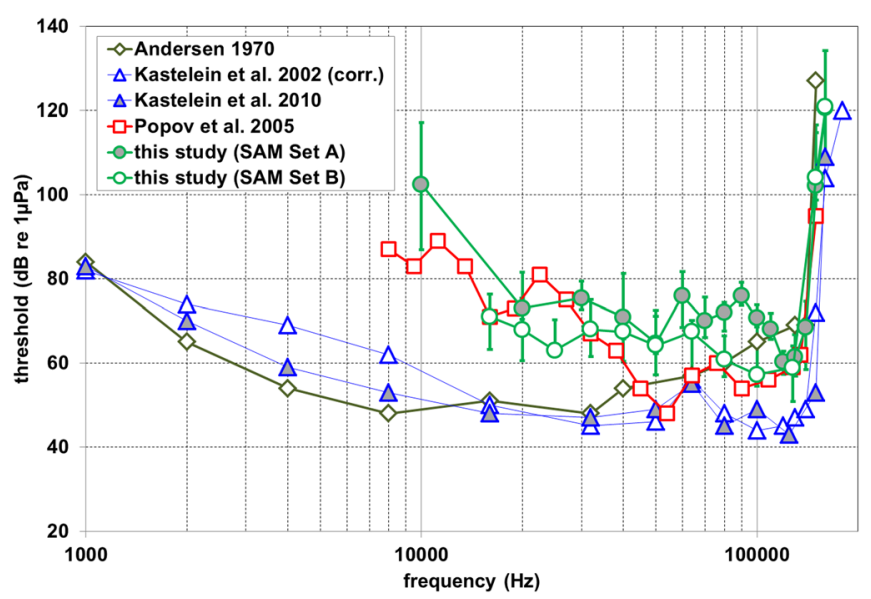

FIG. 9. (Color online) Audiograms on three harbor porpoises using behavioral methods (Andersen, 1970; Kastelein et al., 2002; Kastelein et al., 2010), an evoked potential audiogram on a finless porpoise (Popov et al., 2005) and the median thresholds with the lower and upper quantiles $(0.25$ and 0.75 ) as error bars for the SAM Sets A and B for all thresholds determined in this study. high frequency tails of the audiograms are also consistent with prior comparisons of AEP and behavioral methods in odontocetes, as approaching the low and high frequency limits of hearing generally result in greater differences in thresholds estimated with the two methods (Finneran and Houser, 2006; Houser and Finneran, 2006a; Schlundt et al., 2007; Yuen et al., 2005). Detailed statistical comparison was not deemed useful due to the different methods used and number of animals tested.

The audiogram of the finless porpoise taken from Popov et al. (2005) is the only other study using AEP in a porpoise and shows a comparable form and similar slopes in the ranges of decreasing sensitivity. It is possible that slight differences in the audiograms might be due to true differences in the thresholds of the individuals or species. However, methodological explanations and differences in sample size and analytical methods are also likely contributors. For example, threshold estimates for the Yangtze River porpoise were obtained by establishing a regression line describing the relationship between the spectral amplitude of the ASSR at its modulation frequency to the stimulus level, and tone pips were used instead of SAM tones (Popov et al., 2005). The regression line was then extrapolated to the zeroamplitude crossing of the amplitude axis to obtain an estimate of the threshold. This approach should result in a lower threshold estimate than the method used in this study, which estimated threshold as the midpoint between the lowest stimulus level at which an ASSR was detected and the highest stimulus level at which no ASSR was detected. Based on the two approaches, it might reasonably be expected that if the estimate procedures were consistent that the ranges of best sensitivity might be in better agreement. It should also be noted that greater variability in the audiogram should be expected based on the small sample size $(\mathrm{n}=2)$ of Popov et al. (2005).

The use of AEP methods to test the hearing of wild harbor porpoises produced similar results to those obtained from rehabilitating porpoises under more controlled conditions. In contrast to the results of Mann et al. (2010), which found that a number of stranded odontocetes showed hearing 
deficits, no obvious hearing deficits of harbor porpoises were detected in either the stranded and rehabilitated animals or the animals assessed in the wild. The tested porpoises showed wide variability in hearing thresholds under both conditions, but the audiograms showed gross similarity in the overall range of hearing and patterns of sensitivity. The differences in the spacing of the tested frequencies (in Set A and Set B) likely contributed to the differences observed in the two resulting audiograms. On the one hand, the finer $10-\mathrm{kHz}$ spacing of Set A enabled a finer resolution of the audiogram and it may be that the dip in hearing sensitivity at $120-130 \mathrm{kHz}$ was not well characterized by the overall onethird octave spacing of frequencies in Set B. Conversely, in both sets, 4-SAM stimuli existed with frequency spacing that were less than an octave apart at the highest frequency groupings. This can potentially lead to the influence of an individual component over the ASSR produced by closely spaced neighboring components, particularly if it is presented at high amplitude while the neighboring components are at low amplitude (e.g., near thresholds). Presumably, interactions should be minimized if components are separated by greater than the cochlear filter bandwidth, but high amplitude signals increase the bandwidth of the cochlear filter making interactions more likely (Lins and Picton, 1995). Another factor potentially contributing to the differences in sensitivity is the amplitude modulation rate. The modulation rate transfer function has been assessed in the harbor porpoise (Linnenschmidt et al., 2013; Lucke et al., 2007) and this information was used in establishing the modulation rates used for multiple-SAM tones in this study. In addition, some of the porpoises in this study were used to verify that differences in threshold estimation were not caused by differences in the modulation rate. However, Set A utilized used a lower modulation rate for the testing of some frequencies $(900 \mathrm{~Hz})$, which may have resulted in a suboptimal ASSR amplitude and affected the threshold estimate. Finally, the decrease in hearing sensitivity at $10 \mathrm{kHz}$ (Set A only) is potentially due to a reduction in the effectiveness of the ASSR method at lower frequencies. Threshold estimates were the most variable at $10 \mathrm{kHz}$, which contributed to an elevated mean threshold; thus, the threshold at $10 \mathrm{kHz}$ should be interpreted with caution. Additional care should be given to the background noise in the wild, as this was higher with decreasing frequency in comparison to the trials at the rehabilitation center (Fig. 3). It seems conceivable that the thresholds measured outdoors are more prone to masking.

Rapid development of renewable energy infrastructures in the seas of northern Europe has been a growing concern with respect to potential impacts on harbor porpoises. In general, construction of wind farms or the emission of low frequency sound by operational wind turbines have dominated the concern as to how and to what degree harbor porpoises might be impacted (Brandt et al., 2011; Dähne et al., 2013; Scheidat et al., 2011; Tougaard et al., 2009b). Impacts due to sound exposure are likely within the hearing range of the porpoise and are potentially more severe at frequencies of greatest hearing sensitivity, although recent work in humans suggests that even sound outside the hearing range might potentially impact hearing abilities (Kugler et al., 2014). Although concerns about higher frequency noise from ships have also been speculated as potentially problematic (Hermannsen et al., 2014).

With respect to auditory physiology, sufficient data has been collected that indicates harbor porpoises have a greater susceptibility to auditory fatigue relative to other odontocetes, such as the bottlenose dolphin. Sound exposure levels ( $\mathrm{dB}$ re $1 \mu \mathrm{Pa}^{2} . \mathrm{s}$ ) required to induce the onset of temporary threshold shifts (TTS) in harbor porpoises at frequencies below $10 \mathrm{kHz}$ can be tens of decibels less than that observed in bottlenose dolphins (Finneran et al., 2005; Finneran et al., 2015; Kastelein et al., 2014; Kastelein et al., 2012b; Kastelein et al., 2013a; Lucke et al., 2009). However, sample sizes for TTS and basic hearing studies have been limited and need to be increased in order to address variability in TTS onset and thresholds of hearing. This is true for all hearing related studies (e.g., masking), and is necessary to provide confidence in acoustic impact predictions. As exploration into differences in sensitivity across the range of hearing between porpoises and other cetaceans continues, understanding variability in the range of hearing and hearing sensitivity of the harbor porpoise will be essential for contextualizing behavioral and physiological observations rooted in the porpoises' detection and perception of anthropogenic sound. This is an essential prerequisite in order to enunciate future management strategies and environmental law in relation to noise pollution in the marine environment.

\section{ACKNOWLEDGMENTS}

We are grateful to the Federal Agency for Nature Conservation $(\mathrm{BfN})$ for funding the current project (Z1.253302/2010/14), the German Federal Ministry for Environment, Nature Conversation and Nuclear Safety (BMU) for funding the previous work (FKZ: 0325117) and to the Bundeswehr Technical Center for Ships and Naval Weapons (WTD 71). We thank all volunteers and employees at the SOS Dolfijn for caring for the porpoises. Furthermore, a special thanks to the Danish pound net fishermen. Without their help analysis on free-living porpoises would not have been achievable. Many thanks to Jörg Driver, our expert veterinarian on harbor porpoises. Also may thanks to Ole Meyer-Klaeden, Patrick Stührk, Johannes Baltzer, Steffen Mumme, and Joseph Schnitzler for all their help. Also thanks to all colleagues of the Aarhus University among others Lonnie Mikkelsen, Jeppe Dalgaard Balle, Morten Tange-Olsen, Mikkel Villum, and the crews from the AU \& ITAW who made the field work possible.

Andersen, S. (1970). "Auditory sensitivity of the harbour porpoise Phocoena phocoena," Investig. Cetacea 2, 255-259.

Benke, H., Siebert, U., Lick, R., Bandomir, B., and Weiss, R. (1998). "The current status of harbour porpoises (Phocoena phocoena) in German waters," Arch. Fish. Mar. Res. 46, 97-123.

Bibikov, N. G. (1992). "Auditory brainstem responses in the Harbour porpoise (Phocoena phocoena)," in Fabric characteristics, edited by J. A. Thomas, R. Kastelein, and Ay. Supin, Plenum Press, New York and London, pp. 197-211.

Borcard, D., Gillet, F., and Legendre, P. (2011). Numerical Ecology with $R$ (Springer New York), Vol. 2, 688 pp. 
Brandt, M. J., Diederichs, A., Betke, K., and Nehls, G. (2011). "Responses of harbour porpoises to pile driving at the Horns Rev II offshore wind farm in the Danish North Sea," Mar. Ecol. Prog. Ser. 421, 205-216.

Dähne, M., Gilles, A., Lucke, K., Peschko, V., Adler, S., Krügel, K., Sundermeyer, J., and Siebert, U. (2013). "Effects of pile-driving on harbour porpoises (Phocoena phocoena) at the first offshore wind farm in Germany,” Environ. Res. Lett. 8, 025002.

Dähne, M., Peschko, V., Gilles, A., Lucke, K., Adler, S., Ronnenberg, K., and Siebert, U. (2014). "Marine mammals and windfarms: Effects of alpha ventus on harbour porpoises," in Ecological Research at the Offshore Windfarm alpha ventus, edited by Federal Maritime and Hydrographic Agency and Federal Ministry for the Environment Nature Conservation and Nuclear Safety (Springer Fachmedien, Wiesbaden), pp. 133-149.

Dobie, R. A., and Wilson, M. J. (1989). "Analysis of auditory evoked potentials by magnitude-squared coherence," Ear Hear. 10, 2-13.

Dobie, R. A., and Wilson, M. J. (1996). "A comparison of t test, F test, and coherence methods of detecting steady-state auditory-evoked potentials, distortion-product otoacoustic emissions, or other sinusoids," J. Acoust. Soc. Am. 100, 2236-2246.

Finneran, J. J. (2009). "Evoked response study tool: A portable, rugged system for single and multiple auditory evoked potential measurements," J. Acoust. Soc. Am. 126, 491-500.

Finneran, J. J., Carder, D. A., Schlundt, C. E., and Ridgway, S. H. (2005). "Temporary threshold shift in bottlenose dolphins (Tursiops truncatus) exposed to mid-frequency tones," J. Acoust. Soc. Am. 118, 2696-705.

Finneran, J. J., and Houser, D. S. (2006). "Comparison of in-air evoked potential and underwater behavioral hearing thresholds in four bottlenose dolphins (Tursiops truncatus)," J. Acoust. Soc. Am. 119, 3181-3192.

Finneran, J. J., and Houser, D. S. (2007). "Bottlenose dolphin (Tursiops truncatus) steady-state evoked responses to multiple simultaneous sinusoidal amplitude modulated tones," J. Acoust. Soc. Am. 121, 1775-1782.

Finneran, J. J., Houser, D. S., Blasko, D., Hicks, C., Hudson, J., and Osborn, M. (2008). "Estimating bottlenose dolphin (Tursiops truncatus) hearing thresholds from single and multiple simultaneous auditory evoked potentials," J. Acoust. Soc. Am. 123, 542-551.

Finneran, J. J., Schlundt, C. E., Branstetter, B., and Dear, R. L. (2007). "Assessing temporary threshold shift in a bottlenose dolphin (Tursiops truncatus) using multiple simultaneous auditory evoked potentials," J. Acoust. Soc. Am. 122, 1249-1264.

Finneran, J. J., Schlundt, C. E., Branstetter, B. K., Trickey, J. S., Bowman, V., and Jenkins, K. (2015). "Effects of multiple impulses from a seismic air gun on bottlenose dolphin hearing and behavior," J. Acoust. Soc. Am. 137, 1634-1646.

Götz, T., Hastie, G., Hatch, L. T., Raustein, O., Southall, B. L., Tasker, M., and Thomsen, F. (2009). "Overview of the impacts of anthropogenic underwater sound in the marine environment," OSPAR Commission, London, UK, pp. 1-130. Retrieved from http://qsr2010.ospar.org/media/ assessments/p00441_Noise_background_document.pdf.

Hermannsen, L., Beedholm, K., Tougaard, J., and Madsen, P. T. (2014). "High frequency components of ship noise in shallow water with a discussion of implications for harbor porpoises (Phocoena phocoena)," J. Acoust. Soc. Am. 136, 1640-1653.

Houser, D. S., and Finneran, J. J. (2006a). “A comparison of underwater hearing sensitivity in bottlenose dolphins (Tursiops truncatus) determined by electrophysiological and behavioral methods," J. Acoust. Soc. Am. 120, 1713-1722.

Houser, D. S., and Finneran, J. J. (2006b). "Variation in the hearing sensitivity of a dolphin population determined through the use of evoked potential audiometry," J. Acoust. Soc. Am. 120, 4090-4099.

Huddleston, J. (2010). Understanding the Environmental Impacts of Offshore Windfarms, edited by J. Huddleston, Collaborative Offshore Wind Research into the Environment (COWRIE), Newbury, UK, 154 pp.

Kastelein, R. A., Bunskoek, P., Hagedoorn, M., Au, W. W. L., and de Haan, D. (2002). "Audiogram of a harbor porpoise (Phocoena phocoena) measured with narrow-band frequency-modulated signals," J. Acoust. Soc. Am. 112, 334-344.

Kastelein, R. A., Gransier, R., and Hoek, L. (2013a). "Comparative temporary threshold shifts in a harbor porpoise and harbor seal, and severe shift in a seal," J. Acoust. Soc. Am. 134, 13-16.

Kastelein, R. A., Gransier, R., Hoek, L., and de Jong, C. A. F. (2012a). "The hearing threshold of a harbor porpoise (Phocoena phocoena) for impulsive sounds (L)," J. Acoust. Soc. Am. 132, 607-610.
Kastelein, R. A., Gransier, R., Hoek, L., and Olthuis, J. (2012b). "Temporary threshold shifts and recovery in a harbor porpoise (Phocoena phocoena) after octave-band noise at $4 \mathrm{kHz}$," J. Acoust. Soc. Am. 132, 3525-3537.

Kastelein, R. A., Hoek, L., de Jong, C. A. F., and Wensveen, P. J. (2010). "The effect of signal duration on the underwater detection thresholds of a harbor porpoise (Phocoena phocoena) for single frequency-modulated tonal signals between 0.25 and $160 \mathrm{kHz}$," J. Acoust. Soc. Am. 128, 3211-3222.

Kastelein, R. A., Schop, J., Gransier, R., and Hoek, L. (2014). "Frequency of greatest temporary hearing threshold shift in harbor porpoises (Phocoena phocoena) depends on the noise level," J. Acoust. Soc. Am. 136, 1410-1418.

Kastelein, R. A., Schop, J., Hoek, L., and Covi, J. (2015). "Hearing thresholds of a harbor porpoise (Phocoena phocoena) for narrow-band sweeps," J. Acoust. Soc. Am. 138, 2508-2512.

Kastelein, R. A., van Heerden, D., Gransier, R., and Hoek, L. (2013b). "Behavioral responses of a harbor porpoise (Phocoena phocoena) to playbacks of broadband pile driving sounds," Mar. Environ. Res. 92, 206-214.

Kugler, K., Wiegrebe, L., Grothe, B., Kössl, M., Gürkov, R., Krause, E., and Drexl, M. (2014). "Low-frequency sound affects active micromechanics in the human inner ear," R. Soc. Open Sci. 1, 1-11.

Linnenschmidt, M., Wahlberg, M., and Damsgaard Hansen, J. (2013). "The modulation rate transfer function of a harbour porpoise (Phocoena phocoena)," J. Comp. Physiol. A 199, 115-126.

Lins, O. G., and Picton, T. W. (1995). "Auditory steady-state responses to multiple simultaneous stimuli,” Electroencephalogr. Clin. Neurophysiol. 96, 420-432.

Lucke, K. (2008). "Auditory studies on marine mammals," ChristianAlbrechts-Universität zu Kiel, Kiel, Germany, 159 pp. Retrieved from http://macau.uni-kiel.de/servlets/MCRFileNodeServlet/dissertation_derivate_ 00002646/Dissertation_Klaus_Lucke.pdf?hosts=local.

Lucke, K., Lepper, P. A., Hoeve, B., Everaarts, E., van Elk, N., and Siebert, U. (2007). "Perception of low-frequency acoustic signals by a harbour porpoise (Phocoena phocoena) in the presence of simulated offshore wind turbine noise," Aquat. Mamm. 33, 55-68.

Lucke, K., Siebert, U., Lepper, P. A., and Blanchet, M.-A. (2009). "Temporary shift in masked hearing thresholds in a harbor porpoise (Phocoena phocoena) after exposure to seismic airgun stimuli," J. Acoust. Soc. Am. 125, 4060-4070.

Mann, D., Hill-Cook, M., Manire, C., Greenhow, D., Montie, E., Powell, J., Wells, R., Bauer, G., Cunningham-Smith, P., Lingenfelser, R., DiGiovanni, R., Jr., Stone, A., Brodsky, M., Stevens, R., Kieffer, G., and Hoetjes, P. (2010). "Hearing loss in stranded odontocete dolphins and whales," PLoS One 5, e13824. .

Popov, V. V., Ladygina, T. F., and Supin A. Ya. (1986). "Evoked potentials of the auditory cortex of the porpoise, Phocoena phocoena," J. Comp. Physiol. A 158, 705-711.

Popov, V. V., Supin A. Ya., Wang, D., Wang, K., Xiao, J., and Li, S. (2005). "Evoked-potential audiogram of the Yangtze finless porpoise Neophocaena phocaenoides asiaeorientalis (L)," J. Acoust. Soc. Am. 117, 2728-2731.

$\mathrm{R}$ Core Team (2014). "R: A language and environment for statistical computing," R Foundation for Statistical Computing, Vienna, Austria, https://www.r-project.org/.

Scheidat, M., Tougaard, J., Brasseur, S., Carstensen, J., van Polanen Petel, T., Teilmann, J., and Reijnders, P. (2011). "Harbour porpoises (Phocoena phocoena) and wind farms: A case study in the Dutch North Sea," Environ. Res. Lett. 6, 025102.

Schlundt, C. E., Dear, R. L., Green, L., Houser, D. S., and Finneran, J. J. (2007). "Simultaneously measured behavioral and electrophysiological hearing thresholds in a bottlenose dolphin (Tursiops truncatus)," J. Acoust. Soc. Am. 122, 615-22.

Slabbekoorn, H., Bouton, N., van Opzeeland, I., Coers, A., ten Cate, C., and Popper, A. N. (2010). "A noisy spring: The impact of globally rising underwater sound levels on fish,” Trends Ecol. Evol. 25, 419-427.

Stapells, D. R., Makeig, S., and Galambos, R. (1987). "Auditory steady-state responses: Threshold prediction using phase coherence," Electroencephalogr. Clin. Neurophysiol. 67, 260-270.

Tougaard, J., Carstensen, J., Teilmann, J., Skov, H., and Rasmussen, P. (2009a). "Pile driving zone of responsiveness extends beyond $20 \mathrm{~km}$ for harbor porpoises (Phocoena phocoena) (L)," J. Acoust. Soc. Am. 126, $11-14$. 
Tougaard, J., Henriksen, O. D., and Miller, L. A. (2009b). "Underwater noise from three types of offshore wind turbines: Estimation of impact zones for harbor porpoises and harbor seals," J. Acoust. Soc. Am. 125, 3766-3773.

Tougaard, J., Wright, A. J., and Madsen, P. T. (2015). "Cetacean noise criteria revisited in the light of proposed exposure limits for harbour porpoises," Mar. Pollut. Bull. 90, 196-208.
Wright, A. J., Maar, M., Mohn, C., Nabe-Nielsen, J., Siebert, U., Jensen, L. F., Baagøe, H. J., and J. Teilmann (2013). "Possible causes of a harbour porpoise mass stranding in Danish waters in 2005," PLoS One 8, e55553.

Yuen, M. M. L., Nachtigall, P. E., Breese, M., and Supin A. Ya. (2005). "Behavioral and auditory evoked potential audiograms of a false killer whale (Pseudorca crassidens)," J. Acoust. Soc. Am. 118, 2688-2695. 